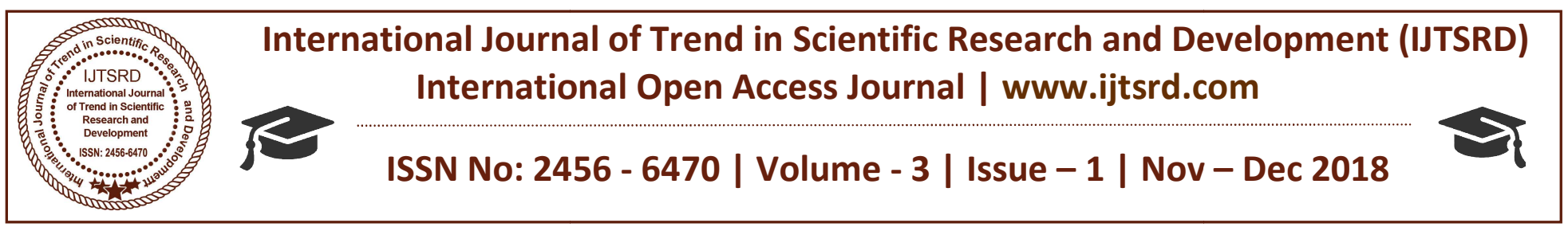

\title{
FEM Simulation of Clinching of Three Steel Sheets
}

\author{
Luboš Kaščák, René Kubík \\ Department of Computer Support of Technology, \\ Technical University of Košice, Košice, Slovakia
}

\begin{abstract}
Clinching is one of a method of mechanical joining processes. The clinching is a cold joining process and belongs to a group of plastic joining technology. A lot of materials are joined in car body production. Some parts of car body construction consist of more than two steel sheets, that are needed to be joined. Three steel sheets of deep drawing quality marked as DC 06 were joined by round clinching tool with a rigid die. FEA Ansys Workbench software was used to simulate the joining of three steel sheets. Due to axisymmetric nature of the clinching process, the simulation was simplified to a 2D representation. Results are presented and discussed in the paper.
\end{abstract}

Key Words: clinching, joining, FEA

\section{INTRODUCTION}

Increasing demands for body in white assembly lead to new solutions for materials and manufacturing. A dissimilar combination of materials and their thickness are specified for a special local requirements of the car body. One of the progressive mechanical joining methods of materials is clinching (CL). Clinching is a process that joins two or more sheets by their plastic deformation, creating interlocking between. The interlocking creation is necessary for the mechanical joints to carry the load [1]. The active parts of the CL tool are a punch, a die and a sheet holder. By moving the punch, the joined materials are drawned into the cavity of the die [2]. The die cavity is specially shaped so that interlocking occurs between the joined sheets. The process of the CL is illustrated in Fig. 1.

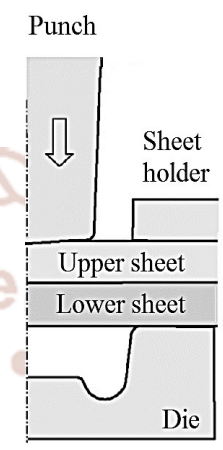

start

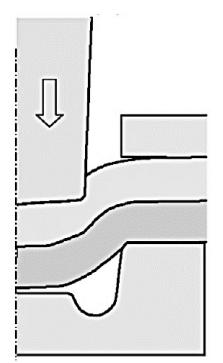

drawing

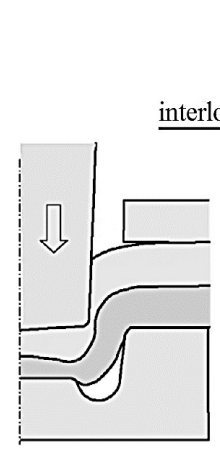

compression
Figure1. The process of clinching

The basic features of the $\mathrm{CL}$ method as well as the mechanical joining include [4]:

$>$ the structure, deformation and residual stress due to thermal influence do not occur in the clinched materials,

a wide range of metals, non-metal materials and their combinations can be combined, possibly combining different thicknesses of the joined materials,

$>$ pretreatment of joined materials is not required in most cases,

materials can be joined without damaging their surfaces or coatings,

$>$ the joining takes place without the emission of any other kind of pollution.

The cross section of typical clinched joints is shown in Fig. 2.

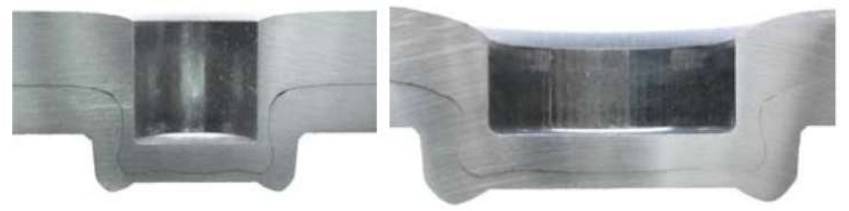

Figure2. Cross section of CL joint 
International Journal of Trend in Scientific Research and Development (IJTSRD) ISSN: 2456-6470

\section{METHODOLOGY OF RESEARCH}

The Anys Workbench 16 software was used for mathematical representation of the problem of joining of three steel sheets of DC 06 deep drawing quality. The task was simplified on a $2 \mathrm{D}$ model because the tools and the joint itself are axially symmetrical. For this reason, the anisotropy of the joined materials will not be considered in the calculation.

A schematic representation of the input geometry of the simulation model with the basic dimensions is shown in Fig. 3. The figure shows limiting conditions of simulation as well. All the degrees of freedom of the nodal points of the die were removed, so that they did not move during the simulation. The nodal points of the punch elements can only be moved in the $Y$ axis, with the punch making a vertical downward movement at a distance of $3.4 \mathrm{~mm}$. The last boundary condition is a force of $400 \mathrm{~N}$ that acts on the body of sheet holder to fix the joined materials during the simulation of the CL joining. Once the prescribed path has been reached, the punch performs a backward movement to the starting position while at the same time the force of the sheet holder ceases to act.

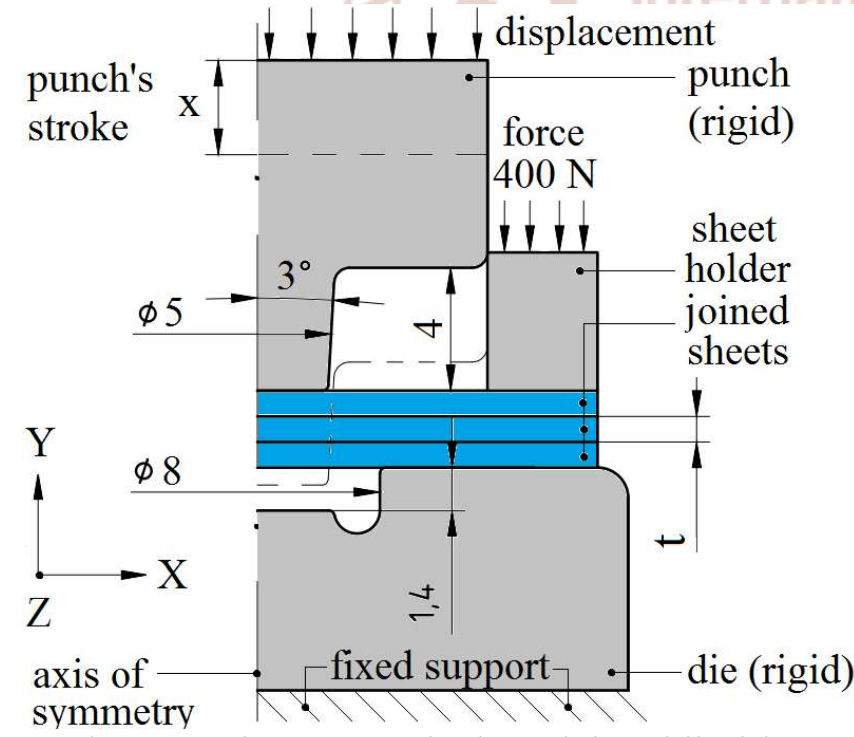

Figure3. The geometrical model and limiting conditions

The punch, die and sheet holder (Fig. 3) in this case were modeled as perfectly stiff, non-deformable bodies. The joined sheets were modeled as deformable bodies, using a multilinear material model to describe the response of the joined material to the load.

The input values for the material model of the joined materials in the form of steel sheets of the quality of DC 06 and thickness of $0.8 \mathrm{~mm}$ are given in Tab. I.
TableI. Input Data Of Material Model

\begin{tabular}{|c|c|c|c|}
\hline Material & $\mathbf{E}[\mathrm{GPa}]$ & $\mathbf{v}[-]$ & $\mathbf{R}_{\mathbf{p} 0,2}[\mathbf{M P a}]$ \\
\hline DC 06 & 210 & 0,3 & 142 \\
\hline
\end{tabular}

The plastic part of the material model was modeled according to the Holomon hardening law. The strain hardening exponent to the equation was determined experimentally, based on a standardized tensile test of the material DC 06.

The Finite Element mesh for joined materials consisted of PLANE 182 elements, i.e. 2D quadrangular elements, which are recommended for simulating 2D axis symmetric problems. The nodes of these elements have two degrees of freedom, which are displacements in each of the axes $\mathrm{X}$ and $\mathrm{Y}$. The size of the elements in the mesh was $0.1 \mathrm{~mm}$. In the case of processes such as clinching, where both the sheet and the finite element mesh are significantly deformed, it is necessary to remesh the elements after certain intervals. This process is known as adaptive remeshing. In this case, the deformation energy criterion which, at defined intervals, controls the deformation energy of each element in the finite element mesh. If the deformation energy of the element exceeds the limits calculated by the program, adaptive remeshing process starts. The two-step simulation consisted of forming the joint (step one) and returning the punch to the starting position together with the sheet holder (step two).

The contacts between the tools and joined materials as well as the contacts between the joined materials were modeled as frictional contacts, using friction coefficients: between tool and sheet 0.12 ; between sheets of 0.2 .

\section{RESULTS AND DISCUSSION}

Fig. 4 shows the development of plastic deformation during the joining of three DC 06 sheets in the four characteristic bonding steps described in Fig. 1.

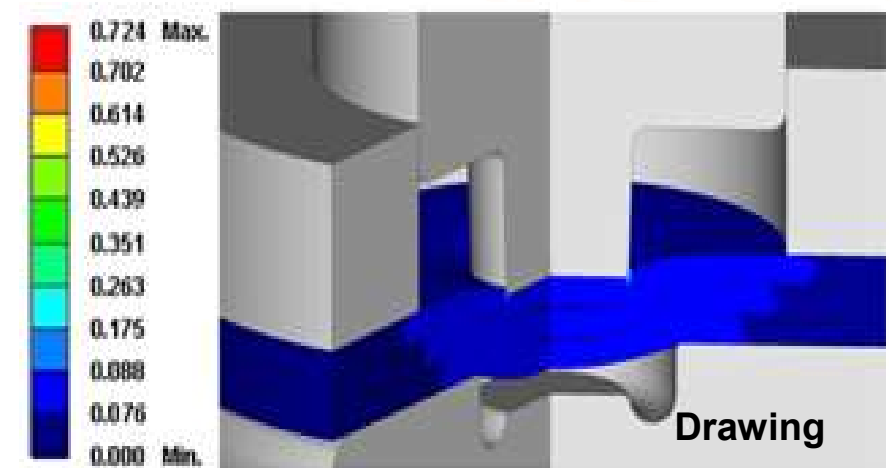


International Journal of Trend in Scientific Research and Development (IJTSRD) ISSN: 2456-6470
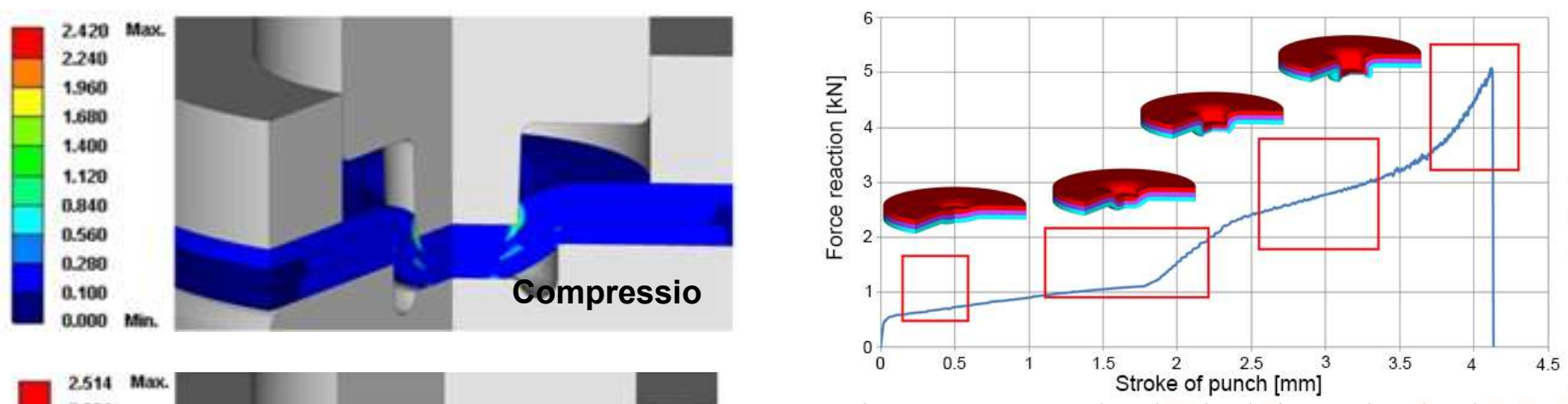

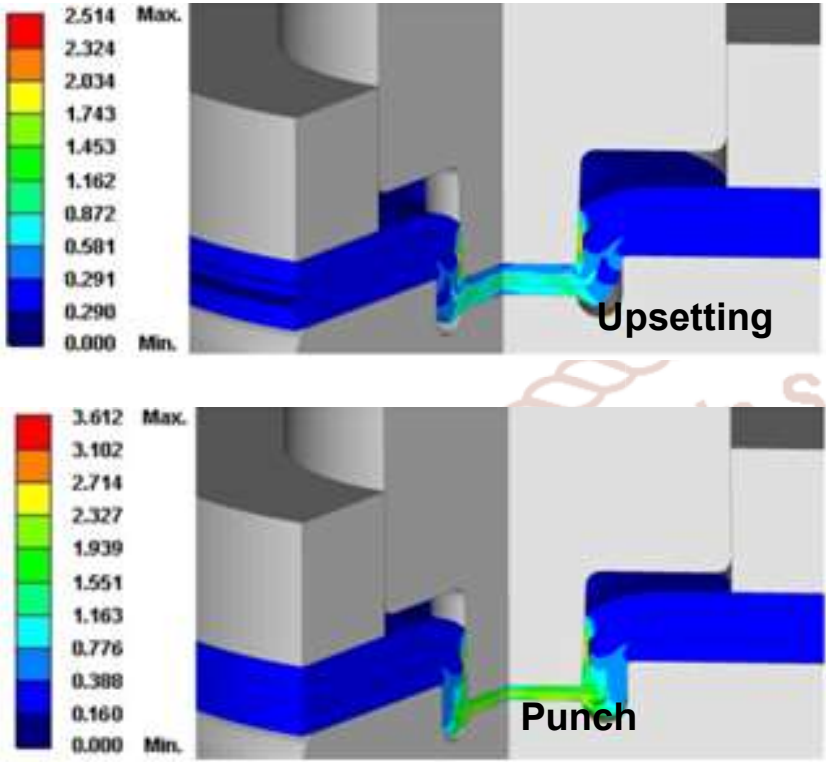

Figure4. Increase in plastic deformation in sheets during CL joint formation
Figure5. Increase in plastic deformation in sheets during CL joint formation

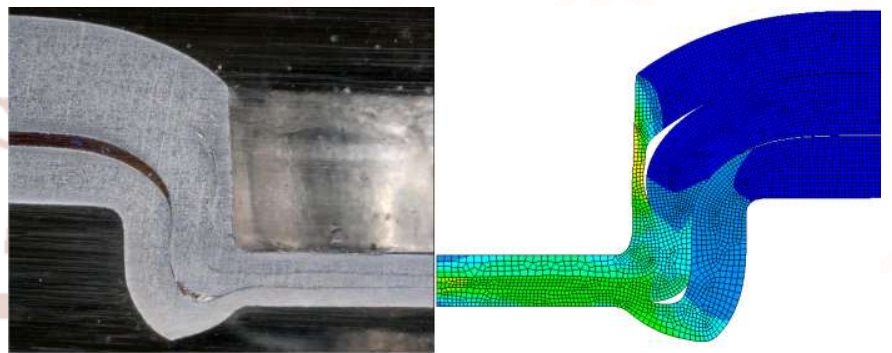

Figure6. Increase in plastic deformation in sheets during CL joint formation

Fig. 6 shows a comparison of the cross sections between the real joint (left) and the joint resulting from the simulation. By comparing the characteristic areas of the two joints, such as the thickness of individual sheets, the thickness of the bottom of the

The $2 \mathrm{D}$ results were expanded by rotation to $3 \mathrm{D}$ views joint or the interlocking between the joined sheets (the so-called "S" shape of the sheets). Based on the visual comparison of the results, it is possible to state with certain 7 tolerance that the simulation results correspond to the result of the actual joining process.

\section{Conclusion}

The paper presented the simulation of the clinching process of the three steel sheets of the deep drawing quality DC 06 with the thickness of $0.8 \mathrm{~mm}$. The simulation has been simplified into $2 \mathrm{D}$ conditions based on the axial symmetry of the entire joining process. The results of the simulation in the form of the representation of the plastic deformation in the sheets during the individual joining stages were presented, where a considerable plastic deformation of the upper sheet (on the punch side) was identified, which reduced to 6 times its thickness during joining process. The calculation was verified by showing the course of the reaction force acting on the punch during the formation of the clinched joint. The comparison of the cross section of the real CL joint and the CL joint obtained by the simulation matched the results between the actual joining process and its simulation. 
ACKNOWLEDGMENT

Author is grateful for the support of experimental works by project KEGA 065TUKE-4/2017 Innovation of educational process in education of $\mathrm{CAD} / \mathrm{CAM} / \mathrm{CAE}$ systems using computational cluster GRID and project APVV-17-0381 - Increasing the efficiency of forming and joining parts of hybrid car bodies.

\section{REFERENCES}

1. P. Kamble, and R. Mahale, "Simulation and Parametric Study of Clinched Joint," Int. Res. J. Eng. Tech., vol. 3, pp. 2730 - 2734, 2016.

2. F. Lambiase, "Mechanical Behaviour of PolymerMetal Hybrid Joints Produced by Clinching Using
Different Tools," Mater. Design., vol. 87, pp. 606 $-618,2015$.

3. J. Mucha, and W. Witkowski, "The Clinching Joints Strength Analysis in the Aspects of Changes in the Forming Technology and Load Conditions," Thin. Wall. Struct., vol. 82, pp. 55 66, 2014.

4. P. Groche, P. et al., "Joining by Forming - A review on joint mechanisms, applications and future trends," J. Mater. Process. Tech., vol. 10, pp. 1972 - 1994, 2014.

5. M. Israel, et al., "Thick Sheet Clinching," Advanced Shipping and Ocean Engineering, vol. 2, pp. 1 - 10, 2013. 